\title{
Connexin 43 expression in the testes during postnatal development of finasteride-treated male rat offspring
}

Agnieszka Kolasa-Wołosiuk ${ }^{1}$, Kamila Misiakiewicz-Has ${ }^{1}$, Irena Baranowska-Bosiacka², Izabela Gutowska ${ }^{3}$, Maciej Tarnowski ${ }^{4}$, Marta Tkacz ${ }^{4}$, Barbara Wiszniewska ${ }^{1}$

\author{
${ }^{1}$ Department of Histology and Embryology, Pomeranian Medical University, Szczecin, \\ Poland \\ ${ }^{2}$ Department of Biochemistry and Medical Chemistry, Pomeranian Medical University, \\ Szczecin, Poland \\ ${ }^{3}$ Department of Biochemistry and Human Nutrition, Pomeranian Medical University, \\ Szczecin, Poland \\ ${ }^{4}$ Department of Physiology, Pomeranian Medical University, Szczecin, Poland
}

Submitted: 30 May 2016

Accepted: 16 August 2016

Arch Med Sci 2018; 14, 6: 1471-1479

DOI: https://doi.org/10.5114/aoms.2016.63022

Copyright (c 2016 Termedia \& Banach

\section{Abstract}

Introduction: Hormone-dependent events that occur throughout the first wave of spermatogenesis, such as cellular communication within seminiferous epithelium during early postnatal testis maturation, are important for adult male fertility. Any changes in the T/DHT ratio in male progeny born from females fertilized by finasteride-treated male rats can result in impairment of testicular physiology. The aim of the study was to verify whether finasteride has a transgenerational effect on the expression of connexin 43 (Cx43), a gap junction protein in testes of the F1 generation.

Material and methods: The subjects of the study were 7, 14, 21/22, 28, and 90-day-old Wistar male rats born by females fertilized by finasteride-treated rats (F1:Fin). The offspring born by untreated rats were used as controls (F1:Control). Connexin 43 was evaluated in the seminiferous epithelium by immunohistochemistry, and in the testis homogenates by Western blot and qRT-PCR. The Cx43 mRNA and protein expression was correlated with intratesticular levels of T and DHT by Spearman's rank correlation coefficient.

Results: We observed a difference in the Cx43 expression in the testis of male rats born by female rats fertilized by finasteride-treated male rats, as compared to the control on following PND (7, 22 and 28 PND, $p<0.001$; 14 PND, $p<0.01)$; and a strong, positive correlation between $C \times 43$ with DHT was only in the F1:Fin group (mRNA: $r s=+0.51, p=0.004$; protein: $r s=+0.54, p=0.002$ ).

Conclusions: Finasteride treatment of male adult rats may cause changes in the communication between the testicular cells of their offspring, leading to a defective course of spermatogenesis.

Key words: connexin 43, finasteride-treatment, testis.

\section{Introduction}

Finasteride, a steroid inhibitor of $5 \alpha$-reductase type 2 ( $5 \alpha$-red2) that inhibits the conversion of T into DHT [1, 2], is widely used for the treatment of prostate cancer, benign prostatic hyperplasia, and androgenetic alopecia [3, 4]. The side effects of finasteride treatment, due to its influence on the sex hormone ratio, are referred to as "sexual side effects"

\author{
Corresponding author: \\ Agnieszka Kolasa-Wołosiuk \\ $\mathrm{MD}, \mathrm{PhD}$ \\ Department of Histology \\ and Embryology \\ Pomeranian Medical \\ University \\ 72 Powstańców \\ Wielkopolskich St \\ 70-111 Szczecin, Poland \\ Phone: +48914661677 \\ E-mail: agnieszka.kolasa@ \\ pum.edu.pl
}


[5], which include low libido and problems with achieving erection and orgasm [6]. Reports also mention decreased semen parameters [7-9] and problems with fertilization [8]. Additionally, recent molecular data demonstrate that finasteride causes sperm DNA damage [10,11], alters sperm morphology in a way that indicates necrosis, and elevates the frequency of diploidy and sex chromosome disomy [12].

In our previous studies we found that finasteride treatment of paternal rats results in altered serum and intratesticular testosterone and dihydrotestosterone levels in their male offspring [13]. Consequently, it can be speculated that finasteride can adversely influence communication within seminiferous epithelium (SE) via the gap junctions during spermatogenesis, modulating the activity of the key enzyme ( $5 \alpha$-red2) involved in metabolism of testosterone. This action is similar to endocrine disruptors (EDs) [14-17] such as flutamide [17-19], bisphenol A (BPA) [20, 21], pesticides [22], and phthalate esters, that change the expression of genes involved in the communication of Sertoli cells and gonocytes [23], crucial for spermatozoa formation $[24,25]$.

Among transcripts for about 20 connexin proteins identified in rodents [24], connexin 43 (Cx43) is the most common and most important isoform of the protein in the male reproductive system [25-31]. Cx43 plays an essential role in testicular development (differentiation of Sertoli cells in genital ridges, colonization of the seminiferous cords by gonocytes, germ cell multiplication and apoptosis, that influence postnatal expansion of the male germ line) $[25,27,28,32-34]$ and is important for the initiation and maintenance of spermatogenesis in adults [24, 32, 35]. Cx43 is widely expressed in diverse testicular cells (Leydig, Sertoli, germ and myoid cells) [32, 35-38]. The expression of $\mathrm{C} \times 43$ within the seminiferous epithelium has a temporal and spatial pattern [39-42] depending on androgen levels, age [40, $41]$, and stage of the SE cycle [26, 38, 42], and is crucial for the formation and functioning of the blood-testis barrier (BTB) [27, 43]. The data on knockout mice demonstrate that, if lacking, $\mathrm{C} \times 43$ cannot be replaced by other types of connexins (Cx26 or Cx32) [44], and homozygous Cx43-deficient $\left(\mathrm{c} \times 43^{-/-}\right)$mice show severe germ cell deficiencies [31].

For this reason we created an experimental animal model to analyze the influence of androgen imbalance on the testes. In the study we estimated the level of Cx43 mRNA and protein in testes homogenates and immunoexpression of $\mathrm{C} \times 43$ within SE during testis neonatal/postnatal maturation in $7,14,21 / 22,28$ day and mature 90-day- old rat offspring born by females fertilized by finasteride-treated males (F1:Fin). The period of study was selected according to the first wave of spermatogenesis in the rat gonad, taking place between the first and the sixth week of life $[45,46]$. During that time, the proper ratio between Sertoli and spermatogonial stem cells is established for appropriate sperm production in the adult [33, 47-49], and any changes in the sex hormone ratio can result in subfertility or even infertility [14]. Additionally, we determined the Spearman's rank correlation coefficient between the levels of $\mathrm{Cx} 43$ mRNA and protein expression, and the intratesticular levels of $\mathrm{T}$ and DHT.

\section{Material and methods}

\section{Animals}

The study was conducted on albino Wistar rats. The parent generation (FO) was used to obtain the following male generation (F1). The experiment was conducted in full accordance with Polish law and with the approval of the Local Ethics Committee for Scientific Experiments on Animals in Szczecin, Poland (Resolution no. 23/2010).

Paternal rats in the F0:Fin group were treated with finasteride (Proscar, MSD, Cramlington, UK) in daily doses of $5 \mathrm{mg} / \mathrm{kg} / \mathrm{bw}$, according to our previous investigations [50-52] and experiments by other researchers $[53,54]$. The period of finasteride treatment before mating lasted 56 days. Male rats received finasteride up to the end of the experiment (for 4-5 months). Once a week, the animals were weighed and their finasteride doses were adjusted.

\section{Generation of filial animals}

The control group (F1:control, $n=30$ ) included male rats born from females fertilized by the control (untreated) male rats. The experimental group (F1:Fin, $n=30$ ) consisted of male rats born from females fertilized by finasteride-treated male rats. The objective of the experiment was to sample the gonads from the $\mathrm{F} 1$ rats at $7,14,21,28$, and 90 postnatal days (PND) of life ( $n=5$ in each age group). The pregnant female rats also gave birth at the weekends, when sections were not possible, so 22-day-old rats were also included in Western blot (WB) and quantitative real-time polymerase chain reaction ( $q R T-P C R$ ) analysis.

The filial generation was collected over a period of 5 months to avoid aging of the parent generation. Detailed information on the design of the animal treatment, mating, and collection is presented in our previous report [13]. After thiopental anesthesia $(120 \mathrm{mg} / \mathrm{kg}$ bw, i.p., Biochemie $\mathrm{GmbH}$, Vienna, Austria), the right testes (5 animals per age group of the F1 generation) were used for im- 
munohistochemical $(\mathrm{IHC})$ reactions while the left testes were frozen and used for WB and GRT-PCR analyses.

\section{Immunohistochemistry (IHC)}

The dissected testes were fixed in Bouin fluid ( $1 \mathrm{~h})$, and then washed with absolute ethanol (3 times over $3 \mathrm{~h}$ ), absolute ethanol with xylene $(1: 1)$ (twice over $1 \mathrm{~h}$ ) and xylene (3 times over $20 \mathrm{~min}$ ). Then, following $3 \mathrm{~h}$ of saturation of the tissues with liquid paraffin, the samples were embedded in paraffin blocks. Using a microtome (Microm HM340E), 3-5 $\mu \mathrm{m}$ serial sections were taken and placed on Polysine-coated histological slides (cat. no. J2800AMNZ; Thermo Fisher Scientific, USA). The sections of the testes were deparaffinized in xylene and rehydrated in decreasing concentrations of ethanol, and then used for immunohistochemical staining. In order to expose the epitopes, the sections were boiled twice in a microwave oven (700 $\mathrm{W}$ for 4 and $3 \mathrm{~min}$ ) in $10 \mathrm{nM}$ citrate buffer ( $\mathrm{pH}$ 6.0). Once cooled and washed with PBS, the endogenous peroxidase was blocked by $3 \%$ solution of perhydrol in methanol, and then the slides were incubated for $60 \mathrm{~min}$ at room temperature with primary mouse monoclonal anti-Cx43 antibody (sc-59949, Santa Cruz Biotechnology INC; final dilution 1 : 500). To visualize the antigen-antibody complex, a Dako LSAB+System-HRP was used (Code K0679; DakoCytomation, Glostrup, Denmark), based on the reaction of avidin-biotin-horseradish peroxidase with $\mathrm{DAB}$ as a chromogen, according to the included staining procedure instructions. Sections were washed in distilled $\mathrm{H}_{2} \mathrm{O}$ and counterstained with hematoxylin. For a negative control, specimens were processed in the absence of primary antibody. Positive staining was defined microscopically (Axioskop Zeiss, Germany) by visual identification of brown pigmentation.

\section{Western blot analysis}

RIPA buffer ( $\mathrm{pH}$ 7.4) containing $20 \mathrm{mM}$ Tris, $0.25 \mathrm{mM} \mathrm{NaCl}, 11 \mathrm{mM}$ EDTA, 0.5\% NP-40, $50 \mathrm{mM}$ sodium fluoride, and protease and phosphatase inhibitors (Sigma, Poland) were used for testis sample homogenization. The total protein concentrations were determined by Pierce, BCA Protein Assay Kit (Thermo Fisher Scientific USA, cat. no. 23227) using bovine albumin as a standard, and homogenates were subjected to SDS-polyacrylamide gel electrophoresis and examined for Cx43 expression. Briefly, the extracted proteins $(20 \mu \mathrm{g} /$ well) were separated on $12 \%$ gel (SDSPAGE) using a Mini Protean Tetra Cell System (Bio-Rad, Poland). The fractioned proteins were transferred onto a $0.2 \mu \mathrm{m}$ PVDF membrane (Bio-
Rad, Poland), and the membranes were then blocked with $3 \%$ BSA in a buffer for $1 \mathrm{~h}$ at RT. Protein expression was determined using primary mouse antibody against connexin 43 (sc-59949, Santa Cruz Biotechnology, Inc.; final dilution 1 : 750) and secondary bovine antibody (antimouse IgG-HRP, sc-2375, Santa Cruz Biotechnology, Inc.; final dilution 1 : 5000). As an internal control $\beta$-actin was used (Sigma-Aldrich; a final concentration of $1.0 \mu \mathrm{g} / \mathrm{ml}$ ). Signals were visualized by chemiluminescence (Thermo Fisher Scientific, USA). ImageJ 1.410 (NIH, USA) was used for densitometric analysis of the bands.

\section{Quantitative real-time PCR (qRT-PCR) analysis}

Quantitative analysis of mRNA expression of connexin 43 was performed in a two-step reverse transcription PCR. Total RNA was extracted from 50-100 mg tissue samples from rat testes using an RNeasy Lipid Tissue Mini Kit (Qiagen, Germany). After determination of the quantity and quality of isolated RNA using a NanoDrop ND-1000 spectrophotometer (NanoDrop Technologies, USA), cDNA was prepared from $1 \mu \mathrm{g}$ of total cellular RNA in a $20 \mu \mathrm{l}$ reaction volume, using a FirstStrand cDNA synthesis kit and oligo-dT primers (Fermentas, USA). Assessment of mRNA levels was performed by quantitative real-time RT-PCR using an $A B I 7500$ Fast instrument with Power SYBR Green PCR Master Mix reagent. Realtime conditions were as follows: $95^{\circ} \mathrm{C}$ (15 s), 40 cycles at $95^{\circ} \mathrm{C}(15 \mathrm{~s})$, and $60^{\circ} \mathrm{C}(1 \mathrm{~min})$. According to melting point analysis, only one PCR product was amplified under these conditions. Each sample was analyzed in two technical replicates, and mean $C t$ values were used for further analysis. The relative quantity of a target, normalized to the endogenous control Gapdh gene and relative to a calibrator, is expressed as $2^{-\Delta \Delta c t}$ (-fold difference), where $C t$ is the threshold cycle, $\Delta C t=$ (Ct of target genes) - (Ct of endogenous control gene), and $\Delta \Delta C t=(\Delta C t$ of samples for target gene) - ( $\Delta C t$ of calibrator for the target gene). The following primer pairs for $\mathrm{C} \times 43$ were used: $\mathrm{F}$ : GAA AGA GAG GTG CCC AGA CAT G; R: AGC ACT GAC AGC CAC ACC TTC.

\section{Statistical analysis}

The results of the Western blot and qRT-PCR analysis were analyzed using Statistica 6.1 software (StatSoft, Krakow, Poland). The arithmetical means and SDs $(x \pm$ SD) were calculated for each of the parameters. Each variable was tested for normality with a Shapiro-Wilk test. As most of the results deviated from a normal distribution, a nonparametric test was used for further analy- 
sis. To assess the differences between the groups, a nonparametric Mann-Whitney $U$-test was used. The probability $p \leq 0.05$ was considered statistically significant. Correlations between the parameters were examined using Spearman's rank correlation coefficient $\left(r_{s}\right)$. Finally, we used Spearman's rank coefficient to determine the correlation between the intratesticular levels of testosterone and dihydrotestosterone, as presented in our previous study [13], and the levels of Cx43 mRNA and protein.

\section{Results}

\section{Immunohistochemistry for Cx43}

In seven-day-old rats from both groups (Figures $1 \mathrm{~A}, \mathrm{~F}), \mathrm{Cx} 43$ immunoexpression was noticeably closer to the base of the seminiferous epithelium (black arrows) and near the large germ cells (gonocytes) (white arrows). The intensity of Cx43-expression was a little stronger in the F1:Fin group, and also visible near the spermatogonia.

In the 14PND F1:Control testes (Figure $1 \mathrm{~B}$ ), the intensity of the immunohistochemical reaction was higher than for F1:Fin (Figure $1 \mathrm{G}$ ), as was visible between germ cells near the base of the SE, but also in the upper part of the epithelium close to the lumen of the tubule. In the F1:Fin rat testes, only a few basally located very early germ cells were encircled by a brown line, indicating the presence of gap junctions (Figure $1 \mathrm{G}$; black arrows).

At PND 21, when the BTB was fully developed, the lumen was visible within the cross sections of the seminiferous tubules of the control and experimental rats (Figures $1 \mathrm{C}, \mathrm{H}$ ); and a Cx43-positive area containing spermatogonia and premeiotic spermatocytes could be seen under the visible line indicating the presence of the BTB (white arrows). This Cx43-positive line in the testes of the F1:Fin group was located a little bit higher in the SE, and under it, more layers (up to 3) of germ cells were located than in the $\mathrm{F} 1$ :Control rats. Moreover, in the F1:Fin group, that BTB-line had a diffuse, discontinuous pattern. Additionally, in the seminiferous tubules of the 21-day-old F1:Control and F1:Fin rats, strongly Cx43-positive large cells were located adluminally (Figures $1 \mathrm{C}, \mathrm{H}$; black arrows).

In 28-day-old control rats, the Cx43-positive line was clear and very visible (Figure $1 \mathrm{D}$; white arrows); it was absent from the F1:Fin group (Figure $1 \mathrm{I}$ ). In both groups of 28-day-old rats, the strongly Cx43-positive large cells were located adluminally (Figure $1 \mathrm{D}$, I; black arrows); but they were less numerous than in F1:Fin.

We observed that in the sexually mature (90-day-old) rat testes from both groups, the $\mathrm{C} \times 43$ expression pattern was dependent on the stage of the seminiferous epithelium cycle (Figures $1 \mathrm{E}$, $J$ and inserts). Generally, the basal region of the SE, containing the spermatogonia and very early spermatocytes (preleptotene), was characterized by weaker $\mathrm{C} \times 43$ expression (Figures $1 \mathrm{E}$, J; white arrows) than in the immature animals (Figures 1 A-D, F-I). Brown pigmentation indicating a positive immunoreaction also had a strandline pattern extending throughout the height of the SE (Figures $1 \mathrm{E}$, J; inserts); the radial motif of the IHC reaction was more evident in the cross-sections of the seminiferous tubules of the F1:Control.

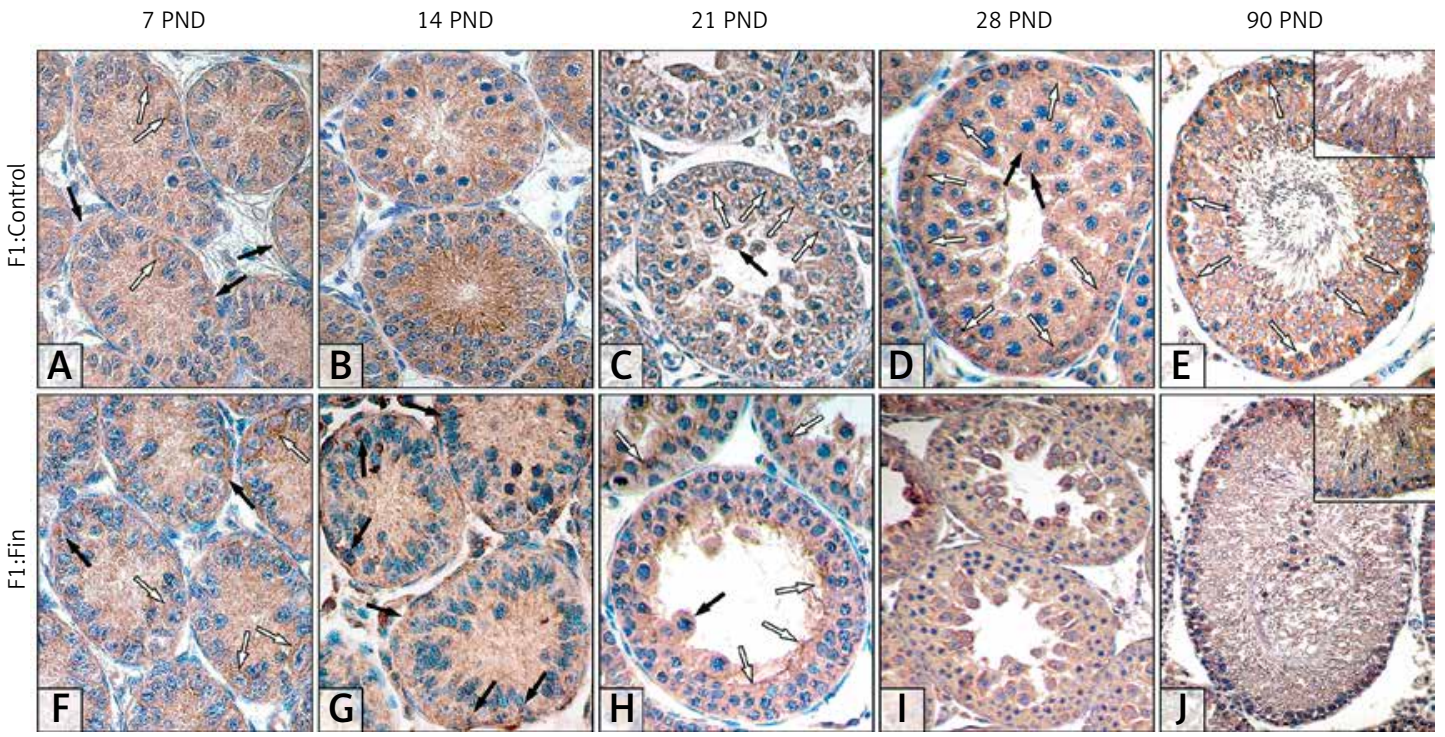

Figure 1. Immunoexpression of connexin 43 (Cx43) within the testes of offspring of female rats fertilized by intact $(\mathbf{A}-\mathbf{E})$ and finasteride-treated (F-J) males. Strong and clearly visible expression of $\mathrm{Cx} 43$ encircling the cells of the seminiferous epithelium or forming a line corresponding to the blood-testis barrier is shown by the black and white arrows, respectively. Objective magnification: A-J 40x. F1:Control, F1:Fin - offspring of female rats fertilized by intact or finasteride-treated males, respectively ( $n=5$ per each age group)

PND - postnatal day. 
Generally, during the first weeks of postnatal development, an increase in Cx43 immunoexpression in the SE was observed and Cx43 expression in premature gonads was higher than in mature gonads. Cx43 expression was lower in F1:Fin than in F1:Control. In order to confirm these results, Western blot analysis was performed.

\section{WB analysis of $\mathrm{Cx} 43$}

The WB analysis showed the presence of the Cx43 protein in the testes homogenates of the 7 , 14, 21, 22, 28 and 90 day old groups of rats (Figure $2 \mathrm{~A}$ ). However, protein expression in the 7 PND testes was under the detection limit for the imaging system used to analyze the optical density of the strands on gel.

In both groups of rats (F1:Control and F1:Fin), we observed a progressive increase in $\mathrm{C} \times 43$ protein expression at the beginning of the first wave of spermatogenesis (in the first weeks of life), and a decrease at the end of this period (Figure $2 \mathrm{~B}$ ).

During the first 4 weeks of postnatal life, the Spearman correlation test showed a statistically significant positive but weak correlation between Cx43 protein expression and the age of prepubertal animals in F1:Control $\left(r_{s}=+0.34, p=0.04\right)$ and F1:Fin $\left(r_{s}=+0.33, p=0.047\right)$. But in the whole period of the experiment (prepubertal and pubertal) the only strong negative correlation was noted between Cx43 expression and animal age in
F1:Fin $\left(r_{s}=-0.90, p=0.008\right)$. Similar to F1:Fin, in F1:Control rats the level of $\mathrm{C} \times 43$ at 14 PND was much lower (2.5 times) than in the mature gonads (90 PND), but the correlation was not statistically significant, which could have been associated with high Cx43 levels at 22 PND. The only statistically significant differences were observed for 28 PND vs. 90 PND, both in F1:Control and F1:Fin ( $p<0.0001$ and $p<0.001$, respectively). When the F1:Control age groups were compared with the F1:Fin age groups, the observed differences were not statistically significant (perhaps due to high standard deviations).

\section{qRT-PCR analysis of Cx43}

Figure 3 shows the differences of Cx43 mRNA levels in each analyzed age group of rats. There were statistically significant decreases of Cx43 mRNA on the analyzed days of growth in the first month of postnatal development of the F1:Fin group when compared to F1:Control (on average, more than two times); that difference was not observed between adult rats (90 PND).

F1:Fin rats showed statistically significant differences in Cx43 mRNA levels between the following days: 22 PND vs. 28 PND, 28 PND vs. 90 PND $(p<0.01)$ and 7 PND vs. 90 PND ( $p<0.001)$. In the control groups of rats, these differences were not statistically significant. In the offspring of finasteride-treated male rats, we found a strong statistically significant positive correlation between
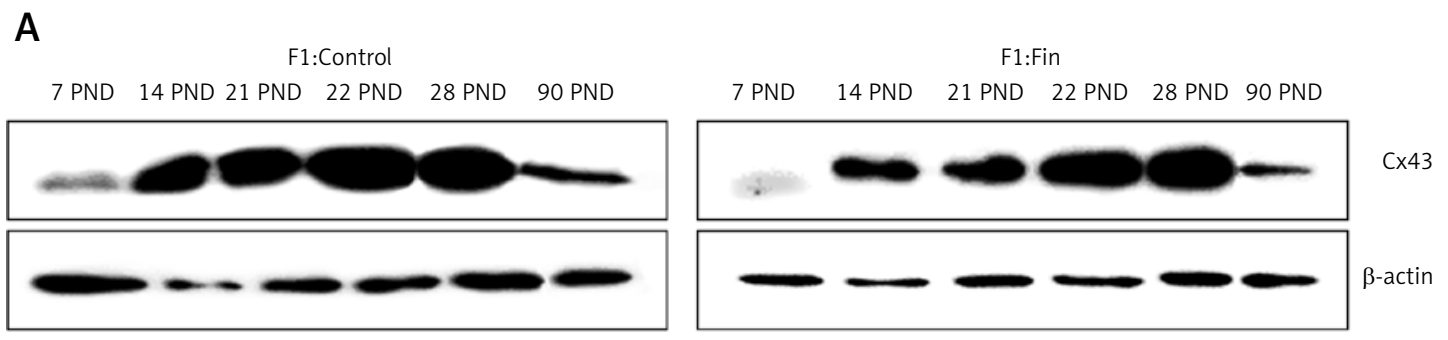

\section{B}

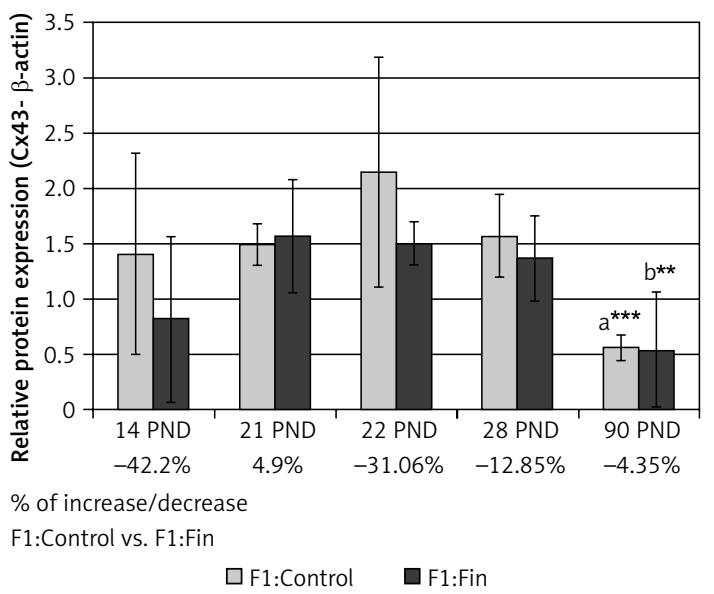

Figure 2. Representative Western blot (A) and densitometry analysis (B) of connexin 43 protein (normalized to $\beta$-actin) in homogenates of testicular tissue of control offspring (F1:Control) and offspring of female rats fertilized by finasteride-treated males (F1:Fin). $\beta$-actin bands as a control for WB procedure. Values in diagram $B$ are expressed as arithmetic means $\pm \mathrm{SD}$; differences were evaluated using the Mann-Whitney $U$-test ( $n=5$ per each age group). Common letters denote statistically significant differences for: 28 PND F1:Control vs. 90 PND F1:Control $\left(a^{* * *} p<0.0001\right)$ and 28 PND F1:Fin vs. 90 PND F1:Fin ( $\left.b^{\star *} p<0.001\right)$. The diagram also shows the percentage of increase/decrease in $\mathrm{Cx} 43$ protein expression of $\mathrm{F} 1$ :Control in comparison to F1:Fin on the selected days of development PND - postnatal day. 


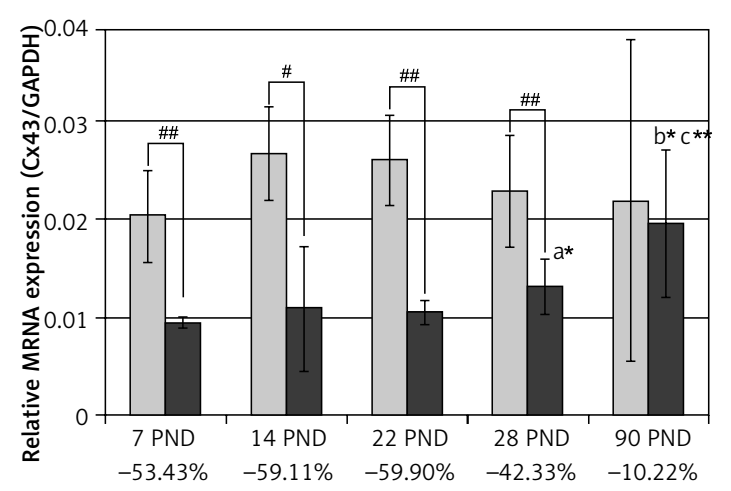

$\%$ of increase/decrease

F1:Control vs. F1:Fin

$$
\square \text { F1:Control } \square \text { F1:Fin }
$$

Figure 3. Representative levels of connexin 43 mRNA (normalized to GAPDH) in homogenates of testicular tissue of control offspring (F1:Control) and offspring of females fertilized by finasteride-treated male rats (F1:Fin). Values are expressed as arithmetic means $\pm S D$; differences were evaluated using Mann-Whitney $U$-test $(n=5$ per each age group). Common letters denote statistically significant differences for F1:Control vs. F1:Fin (\#\# $\left.p<0.001,{ }^{\#} p<0.01\right)$ and 22 PND F1:Fin vs. 28 PND F1:Fin ( $a^{*} p<0.01$ ), 28 PND F1:Fin vs. 90 PND F1:Fin $\left(b^{*} p<0.01\right)$ and 7 PND F1:Fin vs. 90 PND F1:Fin $\left(c^{\star *} p<0.001\right)$. The diagram also shows the percentage of increase/decrease in Cx43 mRNA in F1:Control in comparison to F1:Fin on the selected days of development

PND - postnatal day.

Cx43 mRNA expression and age $\left(r_{s}=+0.69, p=\right.$ $0.0003)$; that relationship was not observed in the control group $\left(r_{s}=-0.097, p=0.51\right)$.

\section{Correlation of intratesticular T and DHT levels with Cx43 mRNA and protein expression}

The average levels of T and DHT in F1:Control and F1:Fin rats at the selected postnatal days are shown in Table I. Because of the small amounts of tissue obtained from the 7-day-old animals, we decided to analyze only the level of DHT, as it is more significant for this study.

There were no correlations between testosterone and $\mathrm{C} \times 43$ mRNA and protein expression in control (mRNA, $r_{s}=-0.26, p=0.218$, protein, $r_{s}=-0.18, p=0.531$ ) as well in F1:Fin rats (mRNA, $r_{s}=-0.25, p=0.238$, protein, $r_{s}=-0.13, p=0.145$ ). However, taking into account the DHT concentration and Cx43 mRNA or protein expression, F1:Fin rats showed positive and moderately strong correlations between these parameters (mRNA: $r_{s}=$ +0.51, $p=0.004$; protein: $r_{s}=+0.54, p=0.002$ ); those dependencies were not found in F1:Control rats (mRNA: $r_{s}=+0.16, p=0.40$; protein: $r_{s}=$ $+0.22, p=0.105)$.

\section{Discussion}

In our study we observed changes in the intensity of Cx43 expression and its location during postnatal testis maturation. These results correlate with other reports that show that the pattern of Cx43 location and escalation changes during testis development, seminiferous epithelium cycle, and gonad aging [26, 38, 40-42, 55]. In the seminiferous epithelium of 7-day-old rats, we observed that a Cx43-positive line encircled the gonocytes and that Cx43 was located near early spermatogonia or the basal region of the epithelium. Similarly, Bravo-Moreno et al. [38] postulated that at birth Cx43 is expressed in the mouse seminiferous cord, between adjacent Sertoli cells, and is localized at the periphery as well as in the cytoplasm projections that surround the centrally localized gonocytes. In 14 PND rats in our experiment, the immunohistochemical reaction was visible in the upper part of the epithelium close to the lumen of the tubule (especially in control

Table I. Testosterone and dihydrotestosterone concentrations in testes homogenates of the offspring of female rats fertilized by intact or finasteride-treated male rats (published in [13])

\begin{tabular}{|c|c|c|c|c|}
\hline \multirow[t]{2}{*}{ PND } & \multicolumn{2}{|c|}{$\mathrm{T}$ [ng/mg] } & \multicolumn{2}{|c|}{ DHT [pg/mg] } \\
\hline & F1:Control & F1:Fin & F1:Control & F1:Fin \\
\hline 7 & NA & NA & $67.75 \pm 11.71$ & $79.40 \pm 12.40$ \\
\hline 14 & $0.37 \pm 0.04$ & $0.36 \pm 0.04$ & $143.97 \pm 10.53$ & $147.26 \pm 16.48$ \\
\hline 21 & $1.26 \pm 0.064$ & $1.23 \pm 0.074$ & $609.11 \pm 61.27$ & $\begin{array}{c}184.42 \pm 38.37^{\star *} \\
\text { vs. F1:Control }\end{array}$ \\
\hline 22 & $2.34 \pm 0.114$ & $\begin{array}{c}1.38 \pm 0.13^{* *} \\
\text { vs. F1:Control }\end{array}$ & $520.18 \pm 98.70$ & $\begin{array}{c}138.306 \pm 52.40^{* *} \\
\text { vs. F1:Control }\end{array}$ \\
\hline 28 & $2.86 \pm 0.15$ & $\begin{array}{c}0.24 \pm 0.19^{* *} \\
\text { vs. F1:Control }\end{array}$ & $120.30 \pm 65.61$ & $82.84 \pm 58.32$ \\
\hline 90 & $0.46 \pm 0.11$ & $\begin{array}{l}0.05 \pm 0.05^{* *} \\
\text { vs. F1:Control }\end{array}$ & $21.43 \pm 9.62$ & $\begin{array}{l}6.78 \pm 3.31^{* *} \\
\text { vs. F1:Control }\end{array}$ \\
\hline
\end{tabular}

F1:Control, F1:Fin - offspring of females fertilized by intact or finasteride-treated male rats, respectively, PND - postnatal day. NA - not analyzed. Values express arithmetic means $\pm S D\left(n=5\right.$ per each age group) evaluated by Mann-Whitney $U$-test. ${ }^{* *} p<0.001$. 
rats); this displacement of $\mathrm{C} \times 43$ is also described by Bravo-Moreno et al. [38], who suggest that the translocation is the result of germinal cell migration. At 21 PND, when the blood-testis barrier is complete (according to $[49,56]$ at about 15-18PND, the physiological BTB is created and the lumen of seminiferous cords opens), we observed a clearly visible Cx43-positive line at the BTB location, which was consistent with the results of Batias et al., who show that $\mathrm{C} \times 43$ colocalizes with the tight-junction-associated protein ZO-1 in the region of the Sertoli cells occluding junctions [57], i.e. at the BTB localization. The Cx43-positive line observed by us at the BTB location in the SE of the 21 PND F1:Fin rats had a diffuse and discontinuous pattern, and was absent in 1 week older rats (28 PND). The results of the IHC reaction indicated an altered, diffuse arrangement or even a lack of a Cx43-positive line at the BTB in premature F1:Fin rats, as well as no evident radial motif that was found in the expression of Cx43 in the SE of 90 PND F1:Control rats. That finding indicates negative consequences for the spermatogenesis of animals born by females fertilized by finasteride-treated male rats.

The observed changes in the intensity of immunoexpression of $\mathrm{Cx} 43$ in the SE were confirmed by the results of qRT-PCR and WB techniques. The analyses showed lower testis Cx43 levels in F1:Fin than in F1:Control, although in WB analysis that change was not statistically significant. Still, Cx43 mRNA levels during the first month of development were more than 2 times lower in the F1:Fin group of rats. These variations in Cx43 expression in our findings could be associated with androgen levels, in accordance with other scientists who have documented androgen-dependent Cx43 expression [17, 58]. In our previous research on the same experimental animal model, we found statistically significant differences in the blood levels of androgens ( $T$ and DHT) and in their intratesticular levels in immature and mature rats born by females fertilized by finasteride-treated male rats, in comparison to the F1:Control groups [13]. T and DHT levels in immature rats were much higher than in mature animals (intratesticular androgen levels achieved a rapid peak in the third week of postnatal life and at the $4^{\text {th }}$ week began to drastically decrease, to reach a significantly lower concentration in the mature gonad), which may have been associated with the greater Cx43 expression in the testes of neonatal rats than in adult rats; and the $\mathrm{C} \times 43$ expression also has a fluctuating pattern. Moreover, at 14 PND, blood $\mathrm{T}$ and $\mathrm{DHT}$ in the F1:Fin rats were half those of the F1:Control groups, while at 22, 28 and 90 PND, the levels of androgens increased (by about $23 \%, 30 \%$, and $98 \%$, respectively) and the DHT level declined 1.6 times compared with the
F1:Control group. The intratesticular T and DHT levels began to decrease from 21 or 22 PND to 90 PND, but the reduction of T was stronger than that of DHT [13]. We documented that the androgen concentrations were closely associated with the changes in Cx43 expression in 14, 21/22, 28 and 90 -day-old rats from F1:Fin groups compared to the respective age groups of the F1:Control rats. In this study, the Spearman's rank correlation coefficient showed positive moderate-strong correlations between intratesticular DHT concentration and Cx43 mRNA and protein only within the F1:Fin groups of rats. Thus, similarly to other endocrine disruptors which produce T/DHT imbalances [17], finasteride may alter gap junctions in the testes. For instance, in vivo studies show that flutamide exposure reduces $\mathrm{C} \times 43$ mRNA both in undescended and descended rat testes and abnormally down-regulates the protein and its distribution in the seminiferous tubules during the embryonic period [18]. In addition, flutamide treatment of pigs decreases the intensity of the Cx43 signal between the interstitial and seminiferous tubule cells, thus blocking androgen action and causing delayed gonadal maturation in later postnatal life [19]. Similarly, a reduction in Cx43 results from neonatal exposure of rats to BPA; however, this also causes an increase in the expression of $\mathrm{N}$-cadherin [20]. A study by Li et al. showed that bisphenol A decreases the levels of connexin 43, N-cadherin and occludin [21]. All of the above suggests that the observed lower expression of $\mathrm{C} \times 43$ in the $\mathrm{F} 1$ :Fin rats compared to the F1:Control adversely influenced the seminiferous epithelium physiology, as the loss of connexin function leads to preferential degradation of occludin-based tight junctions [39].

Possibly, the aforementioned degradation of intercellular junctions results in prematurely sloughed cells of the seminiferous epithelium, as we observed large adluminally located strongly Cx43-positive cells (in a greater number in F1:Fin rats) in the seminiferous tubules of 21-day-old and 28-day-old rats. Similar effects were observed in the neonatal exposure of rats to bisphenol $A$, which altered the expression pattern of Cx43 amongst the sloughed cells in the testes, and resulted in a significant decrease in sperm count [20]. Further correct sperm production in adult gonads requires a proper ratio of spermatogonial stem cells and Sertoli cells [33, 48, 49], established during the first wave of spermatogenesis (in premature testis) when physiological and well-balanced cell apoptosis takes place alongside cell proliferation [59].

As already mentioned, gap junction communication is required for cell proliferation and apoptosis and for the initiation and maintenance of spermatogenesis. The impaired Cx43 expression 
in the gonads from F1:Fin rats (relative to the F1:Control animals) could be associated with the altered apoptosis index in these animals, as we observed in the previous study [13]. In agreement with other authors $[17,19,58]$, any hormonal imbalance caused by exogenous substances with antiandrogen activity that causes a perturbation of $\mathrm{C} \times 43$ expression may lead to developmental testis dysfunction or spermatogenesis arrest as an effect of the disruption of cell-cell interaction. Ultimately, this can lead to subfertility or infertility.

In conclusion, the altered intensity, localization, and pattern of $\mathrm{C} \times 43$ protein immunoexpression in the seminiferous epithelium, as well as changes in Cx43 mRNA and protein levels in testes homogenates of F1:Fin rats compared to F1:Control rats, allow us to conclude that the treatment of adult male rats with finasteride could impede testes physiology in their offspring. Moreover, changes of Cx43 mRNA and protein expression within the F1:Fin group of rats correlated with fluctuation in intratesticular DHT concentration.

\section{Acknowledgments}

This work was financed by the Pomeranian Medical University in Szczecin within the framework of the "Young Scientist" program (MB-16728/11) and "The Fund of Science Stimulation" (FSN-167-03/15).

\section{Conflict of interest}

The authors declare no conflict of interest.

\section{References}

1. Metcalf BW, Levy MA, Holt DA. Inhibitor of steroid 5-reductase in benign prostatic hyperplasia, male pattern baldness and acne. Trends Pharmacol Sci 1989; 10: 491-5.

2. Jin Y, Penning TM. Steroid 5alpha-reductases and 3alpha-hydroxysteroid dehydrogenases: key enzymes in androgen metabolism. Best Pract Res Clin Endocrinol Metab 2001; 15: 79-94.

3. Gormley GJ, Stoner E, Bruskewitz RC, et al. The effect of finasteride in men with benign prostatic hyperplasia. The Finasteride Study Group. N Engl J Med 1992; 327 : 1185-91.

4. The Finasteride Male Pattern Hair Loss Group Study. Long-term (5-year) multinational experience with finasteride $1 \mathrm{mg}$ in the treatment of men with androgenic alopecia. Eur J Dermatol 2002; 12: 38-49.

5. Gur S, Kadowitz PJ, Hellstrom WJG. Effects of 5-alpha reductase inhibitors on erectile function, sexual desire and ejaculation. Expert Opin Drug Saf 2013; 12: 81-90.

6. Irving MS, Kolukula S. Persistent sexual side effects of finasteride for male pattern hair loss. J Sex Med 2011; 8: 1747-53.

7. Amory JK, Wang C, Swerdloff RS, et al. The effect of 5alpha-reductase inhibition with dutasteride and finasteride on semen parameters and serum hormones in healthy men. J Clin Endocrinol Metab 2007; 92: 1659-65.
8. Chiba K, Yamaguchi K, Li F, Ando M, Fujisawa M. Finasteride-associated male infertility. Fertil Steril 2011; 95: 1786.e9-11.

9. Liu KE, Binsaleh S, Lo KC, Jarvi K. Propecia-induced spermatogenic failure: a report of two cases. Fertil Steril 2008; 90: 849.e17-9.

10. Tu HY, Zini A. Finasteride-induced secondary infertility associated with sperm DNA damage. Fertil Steril 2011; 95: 2125.e13-4.

11. Salvarci A, Istanbulluoglu O. Secondary infertility due to use of low-dose finasteride. Int Urol Nephrol 2013; 45: 83-5.

12. Collodel G, Scapigliati G, Moretti E. Spermatozoa and chronic treatment with finasteride: a TEM and FISH study. Arch Androl 2007; 53: 229-33.

13. Kolasa-Wołosiuk A, Misiakiewicz-Has K, BaranowskaBosiacka I, Gutowska I, Wiszniewska B. Androgen levels and apoptosis in the testis during postnatal development of finasteride-treated male rat offspring. Folia Histoch Cytobiol 2015; 52: 236-48.

14. Sharpe RM, Franks S. Environment, lifestyle and infertility - an inter-generational issue. Nat Cell Biol 2002; 4 Suppl: S33-40.

15. Phillips KP, Foster WG. Key developments in endocrine disrupter research and human health. J Toxicol Environ Health B Crit Rev 2008; 11: 322-44.

16. Cowi PA, Foster PMD, Risbridger GP. Endocrine disruption in the male. Part I. The basic biology of endocrine disruption. In: Endocrine-Disrupting Chemicals. From Basic Research to Clinical Practice. Gore AC (ed.). Humana Press, Totowa, New Jersey 2007; 33-62.

17. Hejmej A, Bilińska B. A role of junction-mediated interactions in cells of the male reproductive tract: impact of prenatal, neonatal, and prepubertal exposure to anti-androgens on adult reproduction. Histol Histopathol 2014; 29: 815-30.

18. Cai C, Zhao D, Ma C, et al. Connexin 43 in Sprague-Dawley rat seminiferous epithelium after in utero exposure to flutamide. Syst Biol Reprod Med 2014; 60: 257-62.

19. Kopera I, Durlej M, Hejmej A, et al. Effects of pre- and postnatal exposure to flutamide on connexin 43 expression in testes and ovaries of prepubertal pigs. Eur J Histochem 2010; 54: e15.

20. Salian S, Doshi T, Vanage G. Neonatal exposure of male rats to bisphenol A impairs fertility and expression of sertoli cell junctional proteins in the testis. Toxicology 2009; 265: 56-67.

21. Li MW, Mruk DD, Lee WM, Cheng CY. Disruption of the blood-testis barrier integrity by bisphenol A in vitro: is this a suitable model for studying blood-testis barrier dynamics? Int J Biochem Cell Biol 2009; 41: 2302-14.

22. Defamie N, Mograbi B, Roger C, et al. Disruption of gap junctional intercellular communication by lindane is associated with aberrant localization of connexin43 and zonula occludens-1 in 42GPA9 Sertoli cells. Carcinogenesis 2001; 22: 1537-42.

23. Liu K, Lehmann KP, Sar M, Young SS, Gaido KW. Gene expression profiling following in utero exposure to phthalate esters reveals new gene targets in the etiology of testicular dysgenesis. Reprod Biol 2005; 73: 180-92.

24. Pointis G, Gilleron J, Carette D, Segretain D. Physiological and physiopathological aspects of connexins and communicating gap junctions in spermatogenesis. Philos Trans R Soc Lond B Biol Sci 2010; 365: 1607-20.

25. Cyr DG. Connexins and pannexins. Coordinating cellular communication in the testis and epididymis. Spermatogenesis $2011 ; 1$ : 325-38. 
26. Batias C, Siffroi JP, Fenichel P, Pointis G, Segretain D. Connexin43 gene expression and regulation in the rodent seminiferous epithelium. J Histochem Cytochem 2000; 48: 793-805.

27. Carette D, Weider K, Gilleron J, et al. Major involvement of connexin 43 in seminiferous epithelial junction dy namics and male fertility. Dev Biol 2010; 346: 54-67.

28. Juneja SC, Barr KJ, Enders GC, Kidder GM. Defects in the germ line and gonads of mice lacking connexin 43. Biol Reprod 1999; 60: 1263-70.

29. Kotula-Balak M, Hejmej A, Sadowska J, Bilińska B. Connexin 43 expression in human and mouse testes with impaired spermatogenesis. Eur J Histochem 2007; 51 : 261-8.

30. Lee NP, Leung KW, Wo JY, Tam PC, Yeung WS, Luk JM. Blockage of testicular connexins induced apoptosis in rat seminiferous epithelium. Apoptosis 2006; 11: 1215-29.

31. Plum A, Hallas G, Magin T, et al. Unique and shared functions of different connexins in mice. Curr Biol 2000; 10: 1083-91.

32. Roscoe WA, Barr KJ, Mhawi AA, Pomerantz DK, Kidder GM. Failure of spermatogenesis in mice lacking connex in 43. Biol Reprod 2001; 65: 829-38.

33. Phillips BT, Gassei K, Orwig KE. Spermatogonial stem cell regulation and spermatogenesis. Philos Trans $\mathrm{R}$ Soc Lond B Biol Sci 2010; 365: 1663-78.

34. Gilleron J, Carette D, Durand P, Pointis G, Segretain D. Connexin 43 a potential regulator of cell proliferation and apoptosis within the seminiferous epithelium. Int J Biochem Cell Biol 2009; 41: 1381-90.

35. Brehm R, Zeiler M, Rüttinger C, et al. Sertoli cell-specific knockout of connexin 43 prevents initiation of spermatogenesis. Am J Pathol 2007; 171: 19-31.

36. Decrouy X, Gasc JM, Pointis G, Segretain D. Functional characterization of $\mathrm{Cx} 43$ based gap junctions during spermatogenesis. J Cell Physiol 2004; 200: 146-54.

37. Sridharan S, Simon L, Meling DD, et al. Proliferation of adult Sertoli cells following conditional knockout of the gap junctional protein GJA1 (connexin 43) in mice. Biol Reprod 2007; 76: 804-12.

38. Bravo-Moreno JF, Díaz-Sánchez V, Montoya-Flores JG, Lamoyi E, Saéz JC, Pérez-Armendariz M. Expression of connexin43 in mouse Leydig, Sertoli, and germinal cells at different stages of postnatal development. Anat Rec 2001; 264: 13-24

39. Lee NP, Yeung WS, Luk JM. Junction interaction in the seminiferous epithelium: regulatory roles of connexinbased gap junction. Front Biosci 2007; 12: 1552-62.

40. Knapczyk-Stwora K, Durlej-Grzesiak M, Duda M, Słomczyńska M. Expression of connexin 43 in the porcine foetal gonads during development. Reprod Domest Anim 2013; 48: 272-7.

41. Hejmej A, Kopera I, Kotula-Balak M, Giżejewski Z, Bilińska B. Age-dependent pattern of conexin43 expression in testis of European Bison (Bison bonasus, L.). J Exp Zool A Ecol Genet Physiol 2009; 311A: 667-75.

42. Hejmej A, Kotula-Balak M, Sadowska J, Bilińska B. Expression of connexin 43 protein in testes, epididymides and prostates of stallions. Equine Vet J 2007; 39: 122-7.

43. Li MW, Mruk DD, Lee WM, Cheng CY. Connexin 43 and plakophilin-2 as a protein complex that regulates blood-testis barrier dynamics. Proc Natl Acad Sci USA 2009; 106: 10213-8.

44. Winterhager E, Pielensticker N, Freyer J, et al. Replacement of connexin 43 by connexin 26 in transgenic mice leads to dysfunctional reproductive organs and slowed ventricular conduction in the heart. BMC Dev Biol 2007; 7: 26 .
45. Clermont Y, Perey B. Quantitative study of the cell population of the seminiferous tubules in immature rats. Am J Anat 1957; 100: 241-67.

46. de Rooij DG. Proliferation and differentiation of spermatogonial stem cells. Reproduction 2001; 121: 347-54.

47. Krishnamurthy $\mathrm{H}$, Weinbauer GF, Aslam $\mathrm{H}$, Yeung $\mathrm{CH}$, Nieschlag E. Quantification of apoptotic testicular germ cells in normal and methoxyacetic acid-treated mice as determined by flow cytometry. J Androl 1998; 19: 710-7.

48. Rodriguez I, Ody C, Araki K, Garcia I, Vassalli P. An early and massive wave of germinal cell apoptosis is required for the development of functional spermatogenesis. EMBO J 1997; 16: 2262-70.

49. Morales A, Mohamed F, Cavichia JC. Apoptosis and blood-testis barrier during the first spermatogenic wave in the pubertal rat. Anat Rec (Hoboken) 2007; 290: 206-14.

50. Kolasa A, Marchlewicz M, Adler G, Ciechanowicz A, Głąbowski W, Wiszniewska B. Expression of E-SOD, GPX5 mRNAs and immunoexpression of Cu/ZnSOD in epididymal epithelial cells of finasteride-treated rats. Andrologia 2008; 40: 303-11.

51. Kolasa A, Marchlewicz M, Kurzawa R, et al. The expression of inducible nitric oxide synthase (iNOS) in the testis and epididymis of rats with dihydrotestosterone (DHT) deficiency. Cell Mol Biol Lett 2009; 14: 511-27.

52. Kolasa A, Marchlewicz M, Wenda-Różewicka L, Wiszniewska B. DHT deficiency perturbs the integrity of the rat seminiferous epithelium by disrupting tight and adherens junctions. Folia Histochem Cytobiol 2011; 49: 62-71

53. Ashby J, Tinwell H, Odum J, Lefevre P. Natural variability and the influence of concurrent control values on the detection and interpretation of low-dose or weak endocrine toxicities. Environ Health Perspect 2004; 112: 847-53.

54. Gao W, Kearbey JD, Nair VA, et al. Comparison of the pharmacological effects of a novel selective androgen receptor modulator, the 5alpha-reductase inhibitor finasteride, and the anti androgen hydroxyl flutamide in intact rats: new approach for benign prostate hyperplasia. Endocrynology 2004; 145: 5420-8.

55. Marchlewska K, Kula K, Walczak-Jędrzejowska R, et al. Maturational changes in connexin 43 expression in the seminiferous tubules may depend on thyroid hormone action. Arch Med Sci 2013; 9: 139-45.

56. Russell LD, Bartke A, Goh JC. Postnatal development of the Sertoli cell barrier, tubular lumen, and cytoskeleton of Sertoli and myoid cells in the rat and their relationship to tubular fluid secretion and flow. Am J Anat 1989; 84: 179-89.

57. Batias C, Defamie N, Lablack A, et al. Modified expression of testicular gap-junction connexin 43 during normal spermatogenic cycle and in altered spermatogenesis. Cell Tissue Res 1999; 298: 113-21.

58. Gilleron J, Carette D, Carpentier F, Segretain D, Pointis G. Three dimensional analysis of connexin 43 gap junction in the ex vivo rat seminiferous tubules: short-term effects of hormonal effectors. Microsc Res Tech 2009; 72 : 845-55.

59. Jahnukainen K, Chrysis D, Hou M, Parvinen M, Eksborg S, Soder O. Increased apoptosis occurring during the first wave of spermatogenesis is stage-specific and primarily affects midpachytene spermatocytes in the rat testis. Biol Reprod 2004; 70: 290-6. 